\title{
Diablotextron
}

\section{El deseo de representar: las acotaciones en la obra dramática de Alonso Remón}

The desire to represent: the stage directions in the dramatic plays of Alonso Remón

\section{RAFAEL MASSANET RodRÍGueZ \\ UNIVERSITAT DE LES ILLES BALEARS / INSTITUTO DE ESTUDIOS HISPÁNICOS EN LA MODERNIDAD}

Resumen: En este estudio se ahondará en la capacidad de Alonso Remón para ofrecer directrices en sus comedias. Se comprobará cómo las acotaciones evolucionan a medida que el autor se aleja de las tablas, en un deseo de dejar por escrito su voluntad dramática. El dramaturgo llega a tener en cuenta las posibles disposiciones de los espacios, así como a las compañías. Es también consciente de la presencia del público, por lo que muchas de sus indicaciones precisan el cuidado con el que se debe disponer la tramoya, para no estropear el efecto óptico ante los ojos de los espectadores.

Palabras clave: Alonso Remón; Teatro; Siglo de Oro; Siglo XVII; Acotaciones.

Abstract: This study will address Alonso Remón's ability to offer directives in his comedies. It will be seen how stage directions evolve as the author moves away from the theatrical scene, in a desire to reflect his dramatic will. The playwright takes into account the possible arrangements of the spaces, as well as the theatrical companies. $\mathrm{He}$ is also aware of the public, so many of his indications require the care with which the stage must be arranged, so as not to spoil the optical effect in the eyes of the spectators.

Key words: Alonso Remón; Golden Age; Theater; XVII Century; Stage Directions. 
Despojadas de la elegancia propia de los versos, escatimadas por los dramaturgos, manipuladas por las compañías, maltratadas por los copistas, desatendidas por los lectores, las acotaciones se han visto siempre relegadas a un papel menor respecto al texto dialogado.

Giuliani y Pineda (2018: 7) describen con estas palabras el estado del estudio de las direcciones escénicas de los dramaturgos áureos en el panorama académico actual. Si bien forman parte íntegra del texto, en muchas ocasiones son obviadas, no solo por los lectores, sino también por los propios estudiosos, quienes centran su atención en los diálogos. Estas instrucciones son dejadas de lado en pos de lo considerado como el núcleo de estas obras, y se olvida que son elementos indispensables para la recreación de lo que una vez los autores imaginaron. Sin embargo, pese a que las acotaciones "han tendido a ser el 'patito feo' dentro de los estudios textuales sobre teatro áureo" (Rodríguez-Gallego, 2018: 147) son, sin duda:

el testimonio de una acción efímera e irremediablemente perdida para nuestros sentidos, el clavo ardiendo al que agarrarse para describir un movimiento escénico, un gesto, una escenografía, para reivindicar la materia de la representación (las tablas, los cuerpos, el espacio) frente a las palabras del poeta, y tomar partido en las tensiones milenarias que enfrentan la literatura al espectáculo. (Giuliani y Pineda, 2018: 7)

Las acotaciones, olvidadas en muchas ocasiones por entenderlas como simples instrucciones de uso, contienen en sí mismas gran cantidad de información que puede resultar útil, no tan solo para la puesta en escena del texto, sino también para aspectos filológicos tales como la historia textual de la comedia o las características estilísticas de un autor concreto y su evolución dramática, por no hablar de su labor indispensable para contextualizar la acción de la trama.

Junto al término 'acotación' podemos encontrar el de 'didascalia'. Si bien en principio referenciaban aspectos diferentes, con el tiempo han llegado a emplearse indistintamente. La mayor diferencia que podemos apreciar es su lugar de aparición en el texto, de manera explícita o bien integradas en el diálogo de los personajes. Para la labor de este trabajo, emplearemos ambos términos indistintamente, pues nuestro interés radica en el valor que tienen en la obra del dramaturgo, más allá de las posturas teóricas al respecto. En cuanto a su importancia respecto al texto dramático, la crítica ha adoptado dos posturas: "la concepción de las acotaciones en tanto que metatexto indisoluble de un conjunto 
formado por texto y acotaciones; frente a la delimitación de dos cuerpos disociables, el textual y el didascálico" (Monzó, 2019: 35). Si bien un texto dramático se puede llegar a comprender sin la aparición explícita de estas indicaciones, no podemos negar que se trata de una mutilación del original. Su ausencia supone una deturpación y un oscurecimiento de las distintas etapas de la evolución textual a las que la comedia ha sido sometida (Rodríguez-Gallego, 2018), además de acallar, en cierto modo, la voz del autor. Igual que la prosa no omitiría las descripciones o la poesía sus elementos paratextuales, el teatro no puede ser cercenado de sus acotaciones. Al no considerarlas texto propiamente, es habitual que su valor no sea tomado en consideración y puedan perderse:

La acotación que escribe el ingenio tiene una formulación verbal determinada, pero no hay una voluntad inequívoca de preservarla como tal, sino lo contrario: una libre disposición de esas palabras por parte de quien las lee y las transmite a un nuevo documento (copia de compañía, papel de actor, manuscrito para la lectura, impreso). (Pontón, 2018: 70)

Como podemos comprobar, la acotación es un elemento altamente infravalorado que, sin embargo, resulta indisoluble del cuerpo dramático al que se adscribe. En el intento de organizarlas para una mayor claridad metodológica, nos encontramos la coexistencia de un gran número de propuestas, dependiendo del arbitrio del investigador. Mientras que Bobes Naves (1997) ofrece diez clases entre las que clasificar la acotación, Aston y Savona (1991) presentan seis grandes apartados que, a su vez, engloban hasta 57 posibles tipos, según su función. Otros autores que postulan sus propios sistemas de categorización son Rodríguez Cuadros (1998), Ruano de la Haza (2000), Hermenegildo (2001), García Barrientos (2007), o, en fechas recientes, Monzó (2019). Estos autores diferencian las acotaciones respecto a parámetros tales como el espacio; los personajes y su tipología; cuestiones técnicas de representación; la técnica actoral; o la posición textual de estas indicaciones, es decir, si se encuentran explícitas o implícitas en el dialogo. La disparidad de valoraciones en cuanto a su taxonomía demuestra el amplio trabajo que queda por hacer en esta área y la necesidad de llegar a un lugar común que permita su acercamiento y estudio.

\section{La voz de la acotación}


Pero, ¿a quién pertenecen las palabras de las acotaciones? La primera respuesta plausible que se nos puede ocurrir es, sin duda, al autor, pues el texto de la comedia es su trabajo y su espacio. Mediante sus instrucciones dirige la acción de lo que sucede en escena y mueve a sus personajes como un titiritero invisible a ojos del espectador. Para el lector del texto dramático, se trata del único momento en que se puede "escuchar" su voz, cedida en todo momento a sus personajes, quienes sortean las diversas peripecias que les ha interpuesto. Para Hermenegildo,

son las marcas con que el escritor asegura su presencia. El dramaturgo, desde el lugar que el teatro le reserva, el de las didascalias, trata de mediatizar con su subjetividad el momento de la enunciación del diálogo, el instante de la ceremonia dramática. (2001: 20)

El dramaturgo se convierte en un compositor que va más allá del propio diálogo, construyendo y componiendo no solo un poema, sino su recorrido en las tablas, al tiempo que adquiere el papel de lo que hoy consideramos un director escénico y previendo el espectáculo total. El autor es, siguiendo a Hermenegildo, "sujeto exclusivo de las didascalias" (2001: 20). Las palabras que el público no oirá cuando la obra se represente serán las que verán cuando se ponga en acto la comedia. El lector, por su parte, asistirá a la "muda representación puesta por el poeta en palabras", según una expresión de Robortello en el s. XVI (apud Weinberg, 2003: 77-78).

Sin duda, se trata de una postura más bien teórica e idealizada. En el Siglo de Oro, cuando la comedia salía de imprenta, había pasado por multitud de manos que podían haber modificado las palabras del dramaturgo. E manuscrito original podía haber sufrido modificaciones por parte de autores de comedias, actores, censores e incluso copistas o memoriones. A su vez, el texto que llegaba a imprenta, en muchas ocasiones, no era el original, sino copias que habían sufrido más o menos fortuna. Y si esto ocurría con el texto dramático, mismo destino sufrían las acotaciones:

Casi me atrevería a afirmar que los menos fidedignos en este sentido son los que mejor reflejan el montaje original de una determinada comedia [...]. En algunas ocasiones los cortes, las alteraciones y adiciones que los autores de comedias introducían en el texto del poeta quedaban reflejados en el manuscrito autógrafo; pero en la mayoría de los casos los cambios se hacían en la traslación que servía de cuaderno de trabajo, o en la copia del apuntador [...]. Me aventuro a afirmar que estos traslados poseen por lo general más acotaciones que los manuscritos originales. (Ruano de la Haza, 2000: 46-47) 
Ruano de la Haza afirma que los dramaturgos dejaban en manos de las compañías la escenificación de sus textos, motivo por el que las acotaciones son tan escasas y sencillas:

Podemos, pues, concluir que, en general, un texto, manuscrito o impreso, que contenga una cantidad considerable de acotaciones explícitas, sobre todo para los actores, refleja probablemente la versión escenificada de esa comedia. Por el contrario, una versión cuyas acotaciones ofrezcan opciones al actor [...] procede probablemente del autógrafo. (2000: 49).

Como podremos comprobar a continuación, el estudio de las acotaciones en la obra de Remón nos permite observar la voluntad del autor a través de ellas, así como su evolución a lo largo de su producción dramática. A medida que el mercedario se aleja de las tablas, sus indicaciones se amplían y se vuelven más precisas, lo que revela su deseo por implicarse en la puesta en escena de sus creaciones.

\section{Gloria y olvido de Alonso Remón}

Alonso Remón nació en Cuenca en 1561 y fue un reconocido autor de comedias en su tiempo. Tanto, que muchos de sus contemporáneos lo situaron al mismo nivel que Lope de Vega. Quevedo rememoró sus obras: "Me acuerdo yo antes que si no eran comedias del buen Lope de Vega y Remón, no había otra cosa" (2001: 164); Cervantes ensalzó "los trabajos del doctor Remón, que fueron los más, después de los del gran Lope" (1995: 26); y el propio Fénix le encareció en los siguientes términos:

Fray Alonso Remón, puesto que olvida

las musas por la historia,

Cuenca le ofrezca duplicada gloria,

a sus letras debida,

pues le ha dado más frutos, más tesoro

si los libros son más que plata y oro,

entrando más por ti, dichoso Júcar,

que a España por la barra de Sanlúcar. (Vega, 1950: 191)

Su obra dramática se ha cifrado en torno a las doscientas comedias, pero hoy día solo tenemos registro de poco más de una veintena ${ }^{1}$. Después de vestir el hábito de mercedario en 1605, se alejó de las tablas y abrazó una obra más religiosa, humanista y moralizante, con la que alternó su labor como predicador y cronista de la Orden. Trabajó todo tipo de géneros: comedias, vidas de santos,

\footnotetext{
${ }^{1}$ Serna López $(1967,1982)$ y Placer (1948) consideran una larga lista de comedias como propias o atribuidas a Remón, mientras que Vázquez (2004) limita el número a quince seguras.
} 
manuales de predicación, sermones, crónicas, ensayos de carácter político y cultural, obras de entretenimiento y comentarios y exégesis bíblicas. Su obra, pese a ser extensa, se encuentra a día de hoy sin estudios propios ni ediciones que pongan en relieve la gran labor de este autor.

¿Cuál es la causa del olvido en el que se encuentra sumido pese al reconocimiento público que tuvo en su época? Podemos entender dos principales factores. Primero, que la gran cantidad de obras mencionadas constituya una simple exageración, fruto de la época. Pudiera ser que la fama a la que le encumbran venga promovida por la amistad que le unía a los grandes autores contemporáneos. Por otro lado, el hábito, sin duda, frenaría su desarrollo como autor dramático, pues no habría estado bien considerado que un hombre de Dios se dedicara al vano divertimento, sobre todo teniendo en cuenta su función como predicador. Esta situación habría influido en el hecho de que no mostrase un deseo expreso en conservar o editar sus obras, motivo por el que gran parte de su producción se haya perdido. Sin embargo todo queda en ideas e hipótesis, pues en ningún lado dejó por escrito los motivos y razones por los que se alejó de las tablas.

La división biográfica de Alonso Remón se reflejará también en su producción literaria. Así, encontramos una primera etapa en la que se presenta como dramaturgo, repleta de teatro, rebelde e innovadora, escrita no para conservarse, sino para representarse; y una segunda etapa, religiosa y humanista, asentada en sus oraciones y racional, que sí se ha conservado.

\section{Las acotaciones en las comedias de Remón}

Como hemos comentado, la obra dramática de Alonso Remón se puede dividir en dos grandes bloques. En relación a las acotaciones, se verán afectadas de igual manera, y podemos encontrar grandes diferencias entre una y otra etapa, que dependen, a su vez, de cuestiones relativas al género de la comedia en cuestión, el momento de producción o la complejidad de la escena que se pretende escenificar.

Pasaremos, a continuación, a analizar cómo el dramaturgo hace uso de las acotaciones en sus obras y observaremos si, efectivamente, estas presentan un proceso de evolución, atendiendo a sus dos principales etapas. 


\section{Primera etapa: el dramaturgo}

Este primer período engloba la gran mayoría de obras dramáticas que el mercedario produjo. Se extiende desde 1594, fecha en que se representó por primera vez San Jacinto ${ }^{2}$ —comedia hagiográfica que nunca llegaría a publicarse pero que se conserva manuscrita 3 -, hasta 1610 , momento en el que aparece publicada Las tres mujeres en una. Otros títulos que pueden destacarse de esta etapa serían el Auto del Hijo Pródigo, El rey por su ingenio, El católico español o Grandezas de Madrid, entre otros. Este conjunto de comedias destaca por un tono ligero, siempre asentado, en la medida de lo posible, en el terreno de lo real y cotidiano, alejándose de efectos espectaculares. La presencia religiosa, no obstante, es abundante, ya sea como fuente o en forma de elementos intertextuales que aparecen a lo largo de sus versos, pero siempre desde una visión pragmática. Esta característica trascendería más adelante a su estilo de predicación, en el que la cotidianeidad y la realidad circundante servirían de base para trasladar y enseñar el dogma (Massanet, 2017). Respecto a las acotaciones, las comedias de esta primera etapa presentan un número limitado. A grandes rasgos, nos encontramos indicaciones directas y sencillas, con poco adorno literario, centradas en dirigir la posición o entradas y salidas de los personajes en escena. Esta sencillez da libertad a su interpretación y permite a las compañías una mayor autonomía respecto a su puesta en escena. Los ejemplos que podemos ofrecer responden al tipo de acotación más básica: "Sale Cascabel” (Remón, Tres mujeres en una: f. 9v), "Vase Leoncio" (Remón, 2016a: 501); "Adentro don Beltrán" (Remón, Tres mujeres en una: f. 12). Pautan el transcurrir escénico con claras instrucciones, mientras que la presentación de nuevos personajes en escena siempre mantiene la misma fórmula:

\section{Acción (Entra/Sale) + Nombre + Tipo codificado ${ }^{4}+($ Caracterización de vestuario [si fuere necesario]) (+ Caracterización especial)}

\footnotetext{
2 Según las investigaciones de Fernández Nieto (1974) y Smieja (2000), pero su fecha de composición sería anterior.

${ }^{3}$ En el manuscrito aparece indicado en la portada "Nueva, nunca representada".

${ }^{4}$ Nos referimos a las convenciones estereotipadas por las que se identificaba a los personajes con un tipo o categoría: galán, viejo, dama, criada, gracioso... Habitualmente, llevaban asociado un vestuario que, por su relación, no se molestaban en describir: "El empleo más obvio de la indumentaria de la comedia del siglo XVII es para indicar la categoría social o rango del personaje representado por el actor" (Varey, 1987: 263).
} 
Como en los siguientes ejemplos: "Sale CASCABEL, gracioso, de camino, solo" (Remón, Tres mujeres en una: f. 2); "Sale don JuAN, estudiante, hábito de noche, y BAYONA, capigorrón, de risa" (Remón, 2013: f.1); "Sale SANTO DomINGO, solo, con una cruz pequeña" (Remón, 2016b: 970).

En todos los casos, encontramos los tres primeros elementos que hemos señalado en el esquema anterior. En algunos casos, el autor especificará una caracterización especial del personaje, al introducir alguna pieza de vestuario o utilería con el que debe aparecer. En ningún caso se trata de una indicación gratuita, pues, cual arma de Chéjov, tendrá repercusión directa en la acción de la comedia. Sin embargo, en esta primera etapa, Remón ofrece, en ocasiones, información redundante a través de acotaciones implícitas y explicitas, que no aporta nada a lo que sucede. Como podemos observar en los siguientes ejemplos, el propio diálogo indica las acciones que los personajes deben realizar, por lo que la acotación carece de utilidad:

\begin{tabular}{|c|c|}
\hline Teodoro & $\begin{array}{l}\text { Que a otra mujer disteis fe } \\
\text { van estas sortijas dos. }\end{array}$ \\
\hline Don Beltrán & Ya van. \\
\hline Teodoro & Poneldas \\
\hline Don Beltrán & $\begin{array}{l}\text { En vos } \\
\text { por más cierto las pondré. (Pónele las sortijas) }\end{array}$ \\
\hline Cascab & ¿Qué haces? Es la tapada. \\
\hline Don Beltrán & Necio, no me digas nada. \\
\hline Teodoro & $\begin{array}{l}\text { Pues yo en vos quiero poner } \\
\text { esta cinta. (Pónele la cinta) (Remón, Tres mujeres e }\end{array}$ \\
\hline
\end{tabular}

San Francisco

$$
\begin{aligned}
& \text { Hablémosle con amor, } \\
& \text { y pues su vida acumula } \\
& \text { tanto bien como es razón, } \\
& \text { de esta nuestra concesión } \\
& \text { cada cual muestre su bula. }
\end{aligned}
$$

Tienden dos bulas que trae, cada uno la suya. (Remón, 2016b: 946)

Estas marcas de acción son, por tanto, innecesarias. La acotación refleja un impulso por parte del autor por dejar su marca, hacerse oír y dirigir una supuesta representación, trascender lo que consideraríamos el propio texto literario para insertarse en el discurso escénico. Las noticias de representación de estas comedias ayudan a establecer y afianzar la fama que alcanzó nuestro autor. Este reconocimiento le impulsaría a querer tener cierto control sobre la puesta en escena de su obra. Debido a que la gran mayoría de su producción se 
conserva gracias a copias, no es seguro que todas las acotaciones presentes sean directas de su mano. Sin embargo, tenemos la fortuna de conservar el manuscrito autógrafo de Grandezas de Madrid, cuya autoría no se discute, ya que firma al principio y al final de cada acto. Encontramos un gran número de tachaduras y correcciones. Las acotaciones suelen aparecer en los márgenes, pero en ellas podemos ver un deseo expreso por ir un paso más allá de la simple indicación: "Mientras ha estado refiriéndoselo su padre, don Juan y Bayona se estén cayendo a pedazos de sueño y da viniéndose y estregándose los ojos" (Remón, Grandezas de Madrid: f.4v); "Sale medio dormido" (Remón, Grandezas de Madrid: f.4v); "Lléguese llorando, como loca” (Remón, Grandezas de Madrid: f.20v). A diferencia de los casos anteriores, muchas de estas acotaciones no tienen su reflejo en el propio diálogo o, al menos, no en detalles tan precisos.

La voluntad de Remón por implicarse en la representación de su obra se puede observar en una propuesta de reparto para Grandezas de Madrid. Aparece en el primero de los folios y los miembros parecen corresponder a la compañía de Juan de Morales Medrano. No se limita tan solo a señalar el nombre del escogido, sino también a sugerir o comentar al respecto.

Figuras

Don Diego - Jerónimo López [...]

Juan, su hijo - Juan Morales, o el que hubiere de hacer el galán primero

Bayona, criado de don Juan - Tadeo o el que hiciere el gracioso

Prudencio, ayo de san Juan; Leonardo - Loya

Octavia [...] — La señora Josefa

Cleves, ingeniero - Paredes

Doña Micaela, su hija — La señora María de la [...]

Marina, su criada — La [...] Jerónimo

Valentino - Lobillo. (Remón, Grandezas de Madrid: f.1 $)^{5}$

Este empeño de Remón por tener cierto control de su obra sobre las tablas también trascenderá a las acotaciones de otras comedias. Encontramos desde sugerencias - “Suena rumor de cajas, como que vienen marchando" (Remón, 2016a: 500)_, hasta imposiciones — "Salen tocando su caja delante y el general TEODOsıo detrás. Ha de ser viejo y dice de rodillas" (Remón, 2016a: 501). Llama

\footnotetext{
${ }^{5}$ Hemos intentado reproducir lo más fielmente posible el texto. La apretada y enérgica letra de Remón no permite una lectura sencilla, además de que escribe sobre otras palabras y con otra tinta. El portal MANOS ofrece una identificación más clara entre los personajes y sus correspondientes actores. Sin embargo, en el caso de "Marina, su criada", no compartimos la lectura que ofrece: "Isabel Rodríguez". [https://manos.net/manuscripts/it/vit-163-grandezas-lasde-madrid]
} 
la atención el uso de la perífrasis modal, que demuestra una clara voluntad de intervención en el quehacer de los actores. La imposición, sin duda, vendría dada por la costumbre de repartir los papeles de acuerdo a los miembros de la compañía, y, así, los veteranos se quedarían con los papeles protagonistas, pese a no ser siempre los más indicados. Acertadamente lo refería su compañero de orden y también dramaturgo, Tirso de Molina, al hablar de la causa del fracaso escénico de Don Gil de las calzas verdes:

La segunda causa, prosiguió don Melchor, de perderse una comedia, es por lo mal que le entalla el papel al representante. ¿Quién ha de sufrir, por extremada que sea, ver que habiéndose su dueño desvelado en pintar una dama hermosa, muchacha, y con tan gallardo talle que, vestida de hombre, persuada y enamore la más melindrosa dama de la Corte, salga a hacer esta figura una del infierno, con más carnes que un antruejo, más años que un solar de la Montaña y más arrugas que una carga de repollos, y que se enamore la otra y le diga: ¡Ay, que don Gilito de perlas! Es un brinco, un dix, un juguete de amor...? (Molina, 1913: 340)

Dentro de este primer grupo tenemos que destacar una selección de comedias que presentan unas acotaciones específicas. Si bien habíamos indicado que Remón no busca la espectacularidad, sí hace una excepción cuando las apariciones sobrenaturales toman la escena en comedias de tono religioso. El autor ofrece una escueta descripción del suceso, siempre acompañado de música: "Descúbrase tocando música un trono y aparece un CRISTO crucificado y DIOS PADRE sosteniendo la cruz en forma de Trinidad y humíllase el santo [...] Suena la música y tapan el trono y dice el santo" (Remón, 2016a: 551-552); "Suena música y aparécese NUESTRA SEÑORA cercada de ángeles sobre el altar de la manera que se pinta que sube al cielo" (Remón, 2016b: 977). En ciertas ocasiones, el autor también indicará cómo debe llevarse a cabo alguno de estos sucesos de carácter sobrenatural: "Detrás de la imagen de NUESTRA SEÑORA ha de haber una mujer que, al tiempo que se va san JACINTO, ha de hablar" (Remón, 2016b: 992). Estas escenas siempre responderán a motivos tipificados, fáciles de identificar para los espectadores, de manera que la representación sirva de puente entre el teatro y la doctrina religiosa. Finalmente, en relación a este tipo de acotaciones, tenemos que destacar que 
los personajes de Remón no llegan a contemplar directamente las apariciones sobrenaturales, pero sí interactúan con ellas. Para reforzar este detalle, el dramaturgo se encarga de señalarlo: "En alzando los ojos [san Jacinto], desaparece NUESTRA SEÑORA con música” (Remón, 2016b: 978). El espectador, por su parte, se convierte en testigo privilegiado de todo lo acontecido.

\section{Segunda etapa: el humanista}

A partir de 1605, aproximadamente, la producción dramática del mercedario se detiene para dar paso a un interludio de corte humanista. Alonso Remón se aleja de las tablas y el teatro para centrarse en su faceta religiosa. Pasa a vestir el hábito de la Orden de la Merced, pero no abandona la pluma y continúa escribiendo y publicando obras de diverso género, como textos morales, biografías santas y devotas, crónicas, manuales de predicación, sermonarios, ensayos de carácter político, obras de entretenimiento y comentarios críticos; además de emprender la labor de editar la Verdadera Historia de la Conquista de Nueva España, de Díaz del Castillo.

Volvería nuestro autor a retomar los textos dramáticos casi veinte años después, con la comedia en dos partes El español entre todas las naciones y clérigo agradecido. Algunos críticos (Placer, 1948; Serna López, 1967, 1982; Vázquez, 2004) han querido señalar otras piezas producidas en este interludio, pero su autoría es dudosa y, en muchos casos, muy discutible.

Estas dos comedias aparecieron primero en sueltas, pero pronto se integraron en un volumen titulado Tratado de los reinos orientales, a cargo de Ordóñez de Ceballos. Este libro recoge varias obras y escritos inspirados en la autobiografía publicada por el caballero jienense años atrás, Viaje del mundo6:

En Madrid lo leyó Ramón, un fraile,
y visto tal portento
puso en obra su intento
y dijo su prelado: «Escribe y hazle
dos comedias famosas
(pues no son fabulosas),
y al vivo en casa las representemos,

\footnotetext{
${ }^{6}$ Esta obra en tres volúmenes vio la luz en la imprenta de Luis Sánchez, en Madrid, con el título completo de Viaje del mundo. Hecho y compuesto por el licenciado Pedro Ordóñez de Ceballos, natural de la insigne ciudad de Jaén.
} 
y en verlas todos juntos nos holguemos».

Este doctor famoso y gran poeta, que en el siglo había hecho docientas de provecho como persona sabia y tan discreta, recopiló la historia, sucesos y vitoria; hizo primera parte y la segunda, y en el nombre español su causa funda:

El español entre todas las naciones, como verás, le puso. [...]

El buen prior y fraile me escribieron, y tú verás la carta, y en decir esto basta.

Ambas comedias me las cometieron como en dedicatoria, y aquí irá su memoria para que las imprima y sea claro, que el español en nada es avaro. (Ordóñez, 1629: XXV)

Dentro del mismo prólogo, el dramaturgo incide en la motivación por encargo, pero no precisa quién dio la orden:

La obediencia mandó que yo hiciese aquestas dos comedias y escribiese esta dedicatoria al propio dueño. (Ordóñez, 1629: XXVII)

Si las acotaciones en la primera etapa se caracterizaban por su concisión, veremos en esta segunda cómo evolucionan hacia un mayor despliegue explicativo. Es importante resaltar que estas dos comedias nunca fueron representadas, y, en caso de haberlo hecho, sería en contextos privados, no comerciales. Las comedias recogidas en este volumen son de difícil acceso para un espectador que desconociera la figura de don Pedro Ordóñez de Ceballos, pues se dan por supuesto muchos datos y episodios de su vida. Por poner un ejemplo, la Segunda parte recoge muchos aspectos presentados en la Primera y otras comedias comienzan in medias res, sin proporcionar mayor información contextual. Lo que sí es cierto y hay que destacar es que, al menos en el caso de las comedias de Alonso Remón, el autor sigue fielmente la fuente, llegando a reproducir con gran exactitud y fidelidad pasajes completos, si bien se permite ciertas licencias dramáticas para dotar al texto de agilidad e interés.

Como comentábamos, estas acotaciones presentan un mayor detalle que los casos de la etapa anterior con lo que respecta a la dirección de los actores, con indicaciones que hacen referencia a la gestualidad o al movimiento sobre las tablas. Los personajes, en su mayoría, continúan siendo presentados bajo la 
fórmula antes descrita: "Sale el licenciado don Pedro ORDÓÑEZ de Ceballos, estudiante galán; MARCOS, criado, dómine, de risa; y DOÑA JUANA, al balcón, con un ramillete en la mano" (Remón, 1629a: f.1); "Salen el MARQUÉS de Peñafiel y el CAPITÁN Pedro de Lomelín" (Remón, 1629a: f.2); "Salen la reina FLORA, el EMPERADOR, CAMBANITA, el DOCTOR Acosta y el maestro SAO" (Remón, 1629b: f.1); "Entran don Pedro ORdóÑEZ de Ceballos, de clérigo; el CAPITÁN Pedro de Lomelín, MARcos y MATOSO" (Remón, 1629b: f.2v).

No obstante, para los personajes de origen extranjero, que precisan de una descripción más detallada o concreta para su recreación visual sobre las tablas, Remón incide en rasgos más concretos, en ocasiones tomados directamente del Viaje. Incluso, llega a referir modos actorales: "PoLONIA y los capitanes negros han de traer al cuello un caracol marino. Suene dentro un caracol y entre MARTINILLO, negro valiente. Levántese POLONIA y con coraje dice" (Remón, 1629a: f.13).

En esta segunda etapa, Alonso Remón presta más atención al detalle en cuanto al movimiento y a los modos en que los actores deben desempeñar las acciones. A diferencia de lo que sucede en la primera etapa, el autor indica directamente en las acotaciones la intención con la que deben interpretar el texto: "con coraje dice" (Remón, 1629a: f.13); "Vase furioso" (Remón, 1629a: f.15); "Queda solo don Pedro ORdóÑEZ de Ceballos, pensativo" (Remón, 1629a: f.26); "Éntrase llorosa la reina" (Remón, 1629b: f.28v); "Espántese el príncipe" (Remón, 1629b: f.30v). Deja también muy claro el modo en el que se deben llevar las acciones e, incluso, dónde deben situarse en el espacio los actores, con lo que se puede considerar que Remón siempre tenía en mente la puesta en escena, a fin de dotar de mayor significado a su obra: "Lléguese el licenciado mirando a DOÑA JUANA y cáigasele a ella el ramillete" (Remón, 1629a: f.1v); "Levántalo el licenciado del suelo. Sale DON FRANCISCO y empuñe la espada" (Remón, 1629a: f.1v); "Mete mano a la espada DON FRANCISCO y el licenciado a la daga y sale DOÑA JUANA" (Remón, 1629: f.2); "Quita DOÑA JUANA el ramillete al licenciado de la mano" (Remón, 1629a: f.2); "Sale POLONIA, llena de sangre, la espada desnuda" (Remón, 1629a: f. 15); "Esté cada uno de su parte y DoÑA JUANA en medio" (Remón, 1629a: f.22); "Váyale mirando la reina y LIDAURA le 
lleve la falda. Y sale el REY, que le ha tenido MARCOs a la puerta de la sala hablando con él" (Remón, 1629b: f.6v); "Vaya a entrar con la espada desnuda, deténgalo LIDAURA" (Remón, 1629b: f.9v); "Esté en pie y descubierto, hácele señas que se siente y cubra. Vanse las damas, quedan solos" (Remón, 1629b: f.11v).

Su implicación con la dirección escénica, aunque fuera desde un plano teórico, se refuerza en las situaciones donde dos o más personajes deben enfrentarse en combate. Cuando sucede, Remón introduce las indicaciones de cuándo deben darse de cuchilladas al tiempo que recitan el texto e, incluso, cómo representar entradas y salidas sin que decaiga el ritmo de la refriega7: "Meten mano y éntranse acuchillando" (Remón, 1629a: f.14); "Retírase ORDÓÑEZ, rebatiendo la espada de POLONIA" (Remón, 1629a: f.16); "Métela a cuchilladas, suene dentro armas. Salga el capitán LOMELín con la espada desnuda" (Remón, 1629a: f.16v). Incluso hace uso repetido de la acotación "Afírmanse" (Remón, 1629a: f.17) para indicar a los actores que se apresten para el combate. Su meticulosidad llega incluso al punto de describir cómo simular una estocada y su consecuente herida: "Dale a DOÑA JUANA POLONIA. Traiga sangre en la mano, caiga y finja estar herida" (Remón, 1629a: f.16v).

Un ejemplo interesante en cuanto a la implicación de Remón lo encontramos en la Segunda parte. En un largo parlamento de Ordóñez en el que explica el misterio de su religión al emperador de la Cochinchina, figura la siguiente indicación: "Todas las veces que nombre a María, humillen las cabezas" (Remón, 1629b: f.3). Curiosa acotación que, en un principio, podríamos relacionar con la vertiente religiosa del mercedario. Sin embargo, cuando acudimos a la fuente de la que parte su comedia, descubrimos que se trata de un reflejo directo de las palabras de Ordóñez de Ceballos:

Dijo [el Emperador] con cólera: “¿Cómo se llama su madre de ese Jesús?” Torné a humillar la cabeza y dije María y tornela a humillar. Entonces hizo él lo propio y dijo "María es muy buen nombre y en trayéndome mi mujer, que es hija del emperador de Visnaga, se ha de llamar así [...] Dejemos eso, solo digo de María", y tornó a humillar la cabeza, "que tiene buen nombre y me parece a mí que debía de ser grande señorío, muy hermosa, muy sabia, muy discreta y en

\footnotetext{
7 Debido a las características propias de estas dos comedias, será en la Primera parte donde suceda el mayor número de combates, pues es la que abarca la etapa como soldado de su protagonista.
} 
todo muy buena" [...] Dijo: "Mira, yo quiero tanto a María", y siempre inclinaba la cabeza, "que todo lo que della dijeres me está bien". (1614: ff. 100v-101v).

Remón se muestra preocupado no tan solo por encaminar la puesta en escena de sus obras, sino también por mostrar fidelidad a la fuente de la que parte. Y no se trata del único caso, pues el segundo acto de la Primera parte se inicia del siguiente modo: "Salgan metiendo mano a las espadas dos capitanes y un alférez, el uno tenga pasado el brazo derecho por dos partes con la espada del veedor don Pedro ORDóÑEZ y él la espada del herido, afirmándose con uno de ellos" (Remón, 1629a: f.9v). Este inicio in medias res es un reflejo directo de otro pasaje del Viaje:

El segundo día que llegué a Cartagena, saliendo a la marina, pregunté quiénes eran tres soldados que allí estaban, bravos en sus aspectos y vestidos; dijéronme ser los dos capitanes y, el otro, alférez; llegué $y$, hecho el comedimiento debido, estuve un rato en conversación con ellos; y, apartándose el un capitán, dijo: "Vámonos de aquí, señor capitán, que ya todos se nos atreven"; y volviendo las espaldas me dio ocasión a tirarle de un brazo, diciéndole: "Yo soy veedor general de estas armadas y he sido alférez, y me puedo llegar a conversación de capitanes y de gente principal como vuestras mercedes, porque lo soy yo". Agraviose de mis razones y dijo: "Apartémonos de aquí a esta marina". Fuéronse delante los dos capitanes y el alférez y yo; y, transpuestos en un lugar donde no podíamos ser vistos de la ciudad, echamos manos a las espadas, y permitió Dios que a pocas tretas se arrojase con una estocada a mis pechos, que es el medio de proporción que llaman los diestros de filo al cuerpo, y, bajando la muñeca le di por la suya una estocada que le pasé el brazo dos dedos de la muñeca y luego por el molledo, y con la furia que él venía entró la espada de tal manera que queriéndola sacar no pude, y la suya se le cayó, y en un pensamiento la así y me defendí, porque venía descargando un golpe el otro capitán. El alférez echó mano y se fue hacia él, diciéndole: "Señor hermano (porque lo eran), deténgase vuestra merced, y si no perderé el respeto a la mayoría"; y así se reportaron y yo me aparté y le sacaron la espada y me la trajo. Atadas las heridas, se fueron los capitanes, y el alférez y yo por otra parte. Pidiome no lo entendiese nadie y después nos hizo amigos. (Ordóñez de Ceballos, 1614: ff.34v-35)

Pese a la fidelidad mencionada, Remón se permite introducir ciertas licencias dramáticas, sobre todo de corte cómico, a través de las acotaciones que se refieren al personaje de $\mathrm{Marcos}^{8}$, a quien le asigna el rol de gracioso. Es interesante observar como las acotaciones refuerzan la comicidad física que ya de por sí muestran sus diálogos. Veamos un ejemplo: "Salen indios con un baile. Sacan a MARCos desnudo puesto en un asador" (Remón, 1629a: f.22). Si esta

\footnotetext{
${ }^{8}$ Marcos Ortiz es un personaje histórico, natural de Jerez, que acompañó a don Pedro Ordóñez de Ceballos en muchas de sus aventuras como su criado. Su desarrollo como gracioso en las comedias es una licencia que toma Remón y que no tiene su reflejo en Viaje del mundo.
} 
sola presencia sería motivo de hilaridad, cuando los protagonistas acuden a liberarle ocurre lo siguiente: "Suenan cajas y armas. Salgan indios huyendo y vuelvan con MARCos. Suéltenlo y huyan. Sale don Pedro OrdóÑEZ con espada y rodela tras dellos" (Remón, 1629a: f. 22v). Es en este tipo de acotaciones donde se puede vislumbrar la voluntad del autor, pues trasciende la labor de poner en verso la biografía para dotar a su comedia de recursos propios.

Al igual que ocurría en las comedias de la primera etapa, las apariciones tienen su propio espacio en estas comedias. Estas situaciones de carácter milagroso precisan de una maquinaria teatral específica para poder representarse. Remón detalla los elementos que comprende la escena pero, también, el proceso, mecánico y actoral:

Música. Tiren una cortina. Descúbrase un fraile francisco en el aire y arriba un ángel anunciando a nuestra señora de la Encarnación y en medio una cruz. El ángel baje. $\mathrm{Y}$ al otro lado, Cristo sube resucitado, glorioso. $\mathrm{Y}$ así como ellos pasan mirándolo, se va encubriendo todo, dando fin al primer acto" (Remón, 1629a: f.9v).

Sin palabras, a través tan solo del empleo de imágenes, Remón consigue transmitir una enseñanza, mecanismo que entronca directamente con su faceta como predicador. El mercedario, gran conocedor del signo religioso, muestra una gran preocupación por el ornato y el simbolismo en este tipo de escenas y, al igual que ocurre con los emblemas o las reproducciones pictóricas en las iglesias, pretende trasmitir una lección codificada para el público. Por ese mismo motivo, es destacable la presencia del Demonio en la Segunda parte. Cuando un bonzo lo invoca, "ábrase una boca de infierno, con muchas llamas de fuego y salga el DEMONIO en figura de mujer" (Remón, 1629b: f.30v). Además de la espectacularidad que se conseguía con esta maléfica aparición, Remón introduce un elemento poco común: la identificación de este ser con una mujer. Si bien este tipo de disfraz es un recurso que el demonio emplea para engañar y seducir a sus víctimas ${ }^{9}$, en este caso se trata de la forma que adopta para

\footnotetext{
9 Fothergill-Payne señala como "la principal característica del Diablo el ir de incognito" y que puede adoptar diversos disfraces "como 'doncella seductora', como 'pulido galán', como 'viejo venerable' o 'con la capa del Bien'. El incógnito del Diablo es su arma más eficaz, al miso tiempo que subraya la índole engañosa del ser diabólico, que representa la negación de todo y por eso es un 'no-ser', es el caos, la nada" (1977: 118). Además de por el recurso estilístico y espectacular que ofrece el cambio de apariencia, también tiene un innegable "valor en la creación del suspense: un demonio disfrazado ofrece al dramaturgo un elemento con enorme potencial dramático" (Fernández González, 2005: 264).
} 
aparecerse directamente desde el infierno. El hecho de que el género del personaje no aporte valor alguno a la situación que se desarrolla, y que sea una caracterización tan peculiar, nos hace pensar que se trata de una decisión intencionada por parte del dramaturgo. Dicho episodio tampoco corresponde con la fuente y se trata, por tanto, de una licencia tomada por el autor. Cuando el Demonio hace acto de presencia, se limita a relatar el futuro de Ordóñez de Ceballos y, al acabar su discurso, sale de escena mientras persigue al gracioso. No podemos conocer los motivos que le impulsaron a escoger tal representación, pero, sin duda, es un elemento más que debemos considerar para establecer la impronta personal del autor en las acotaciones.

Por último, quedan por comentar las acotaciones que hacen referencia a elementos escenográficos. Son bastante escasas, en comparación con el resto del conjunto y, en su gran mayoría, solo introducen elementos contextuales para que pueda llevarse a cabo la escena. Sin embargo, encontramos casos especiales que ofrecen instrucciones concretas de los elementos que deben aparecer. Cuando esto sucede, se debe, nuevamente, a la fidelidad que Remón se esfuerza en conseguir:

Tiren una cortina y aparezca una montaña hecha de lienzo, con unas palmas, aunque sean pintadas, cubierto de hierbas, donde esté hecha la casa del Sol, un arco y altar y a los dos lados el Sol y la Luna y en medio en un trono doña Juana, con rayos en la cara como los del Sol. (1629: f.23v)

El espacio que se despliega a ojos de los espectadores es la Casa del

Sol, de la que Ordóñez ofrece detallada descripción en su Viaje:

En este tiempo me dijo la india que aquellos buhíos eran la Casa del Sol, y que estaban los caciques echando suertes si habían de vencer o servir a los españoles. [...] Y mirase que había dos puertas en cada buhío y en el grande que no había más de una estatua toda la riqueza del mundo, tres bultos de oro, que era el Sol, Luna y Lucero, marido, mujer e hijo, que eran sus dioses [...] Yo y Pedro de Lomelín entramos otros tres aposentos, que se pasaba del uno al otro y vimos los ídolos. El mayor arrimado a la pared y el otro que le daría a los pechos delante y el chico que no llegaría a la cintura de la Luna, del cual nos abrazamos y de ningún género lo pudimos levantar. (1614: f. 56)

Tenemos que destacar cómo Remón matiza su acotación - “aunque sean pintadas" - , pues, por un lado, refuerza la necesidad de ese elemento en escena $y$, por otro, demuestra la consciencia del autor respecto a las posibilidades de primera mención a un demonio disfrazado de mujer en la comedia nueva. 
representación de su obra y las dificultades que una compañía pudiera encontrarse para la puesta en escena.

La música es también un elemento de gran presencia en estas dos comedias. No solamente funciona como un acompañamiento para la entrada de seres sobrenaturales o como una llamada a la batalla en escenas bélicas, sino que también posee un componente lúdico que ayuda a recrear la magnificencia de la escena en la que se encuentran los personajes:

Música de atabales. Grande acompañamiento. Los bajaes Alí Erbago y MAHOMAD, DON JUAN de Cardona, el CAPITÁN Pedro de Lomelín, el alférez don Pedro de ORDÓÑEZ de Ceballos, el dómine MARCOS, de figura de risa. Pongan criados moros los manteles en el suelo sobre alfombras y todos siéntense. (Remón, 1629a: f.6v)

Levanten las mesas y hagan un modo de baile y sarao y saquen a bailar las moras a los cristianos o como mejor pareciere. Échese el resto. (Remón, 1629a: f.7v).

Como podemos observar, se vislumbra un deseo de espectacularidad visual pero, al mismo tiempo, libertad en la puesta en escena, al ofrecer la pincelada general, pero sin entrar en el detalle. Encontramos más casos a lo largo de estas dos obras:

Vase. Cajas a orden de marchar. Delante presos y rendidos indios y CALOco y POLONIA, BARTOLOMÉ Pérez y detrás don Pedro ORDÓÑEZ. Una vistosa entrada. (Remón, 1629a: f.24v)

Suene toda la música que se pueda por dos partes y salgan por la una gentilhombres, a la postre dos fuentes, una con la corona y otra con un cetro, hínquense de rodillas. $Y$ por la otra parte, con diferente música, damas con fuentes, las donas, cuello o valona, y camisas, hínquense de rodillas. Un paso de consideración. (Remón, 1629b: f.15v)

Entran por dos partes diferentes a un mismo tiempo con acompañamiento el REY con la REINA de la mano y damas. Y por otra la INFANTA, vestida de monja de la Concepción, y MATILDE, la mujer de CAUDONITA, muchas fuentes de plata, muchos cristianos y el padre PEDRO, y los demás cristianos. Y den vuelta como más convenga. Una entrada vistosa y música. (Remón, 1629b: f.32v)

Quizás, el hecho de tratarse de una comedia de encargo, que no sería representada en teatros comerciales, diera libertad a Remón para imaginar grandes escenarios repletos de suntuosidad, personajes y elementos. Este tipo de acotaciones en la primera etapa no aparecen y se limitan a instrucciones mucho más claras, concretas y, sin duda, prácticas para su representación. Por eso, es sorprendente encontrarnos con el siguiente caso en los últimos compases de la Segunda parte: "Entren con una trompeta MARCos, en un rocín, vestido de moro, tapado el rostro, y el PRínCIPE a caballo, tapado el rostro con una banda, lanza y adarga, que se han de ver desconocidos" (Remón, 1629b: 
f.33). La entrada de estos caballos, junto al toque de trompeta y la gran cantidad de personajes reunidos en escena, causaría una gran impresión al hipotético público que asistiera a la representación. Sin embargo, la irrupción de ambos personajes no sirve para solucionar ninguna de las líneas de acción abiertas y tampoco se trata de reproducir en escena fielmente ninguno de los sucesos del Viaje. El aspecto espectacular se superpone, por tanto, a la narración y a la fidelidad de la comedia. Tal vez por eso Remón se permita esta licencia, como un último remate a su carrera como dramaturgo, acabando su obra, y él mismo, por todo lo alto.

\section{Conclusión}

Como hemos podido comprobar, las acotaciones son un elemento de gran valor que permiten conocer y estudiar la evolución de la personalidad escénica del dramaturgo. Las comedias con las que Alonso Remón inicia su andadura en las tablas presentan acotaciones sencillas y concisas, necesarias para la puesta en escena de las situaciones que plantea, pero sin extenderse fuera de los márgenes que marcan las convenciones del género. No será hasta que se libere de dichas restricciones que la verdadera voluntad del autor pueda ser percibida a través de la voz de las acotaciones, mientras cede el dialogo a sus personajes. La distancia que toma respecto al mundo del teatro en su segunda etapa, y el hecho de no estar escribiendo para el gran público, le permite plasmar en su obra su propia visión del espectáculo. Remón, por tanto, ofrece al lector todo un abanico de posibilidades, tanto para la comprensión como para la representación de su obra, al tiempo que se descubre como un autor que trasciende su propia escritura al manifestar un deseo por representarla.

\section{BiBLIOGRAFÍA}

Aston, Elaine y SavonA, George (1991). Theatre as Sign System. A Semiotics of Text and Performance. London: Routledge.

Bobes NAVES, María del Carmen (1997). Semiología de la obra dramática. Madrid: Arco Libros.

Cervantes, Miguel de (1995): Ocho comedias y ocho entremeses. El trato de Argel. La Numancia. Viaje del Parnaso. Poesías sueltas, ed. Florencio Sevilla Arroyo y Antonio Rey Hazas. Alcalá de Henares, Centro de Estudios Cervantinos. 
DuRÁ Celma, Rosa (2016): El teatro religioso en la colección del conde de Gondomar: el manuscrito 14767 de la BNE, Tesis Doctoral, Valencia.

FERnÁNDEZ NiETo, Manuel (1974). Investigaciones sobre Alonso Remón, dramaturgo desconocido del siglo XVII con dos comedias inéditas. Madrid: Retorno.

FOTHERGILL-PAYNE, Louise (1977). La alegoría en los autos y farsas anteriores a Calderón. Londres: Tamesis.

GARCÍA BARRIENTOS, José Luis (2007). Análisis de la dramaturgia: nueve obras y un método. Madrid: Fundamentos.

GIULIANI, Luigi y PINEDA, Victoria (2018). "Presentación o loa”. En Luigi Giuliani y Victoria Pineda (eds.), "Entra el editor y dice": ecdótica y acotaciones teatrales (siglos XVI y XVII). Venecia: Ca'Foscari.

GoNZÁLEZ FERNÁNDEZ, Luis (2005). "El traje de demonio en la comedia de santos". En Isabel Ibáñez (coord.), Similitud y verosimilitud en el teatro del Siglo de Oro. Pamplona: EUNSA, pp. 263-282.

"Grandezas (Las) de Madrid", en https://manos.net/manuscripts/it/vit-163grandezas-las-de-madrid [Fecha de consulta: 20 de febrero de 2020].

HermenegILDO, Alfredo (2001). Teatro de palabras. Didascalias en la escena española del siglo XVI. Lleida: Edicions de la Universitat de Lleida.

MASSANET RodRíguez, Rafael (2017). "La Espada sagrada de Alonso Remón: método para enseñar a los nuevos predicadores". En Anna Bognolo; Florencio del Barrio de la Rosa; María del Valle Ojeda Calvo; Donatella Pini y Andrea Zinato (eds.), Serenísima palabra: actas del $X$ Congreso de la AISO. Venecia: Ca'Foscari, pp. 751-760.

Monzó, Clara (2019). Poética de la acotación en la dramaturgia de Calderón de la Barca. Tesis Doctoral. Valencia.

Ordóñez de Ceballos, Pedro (1614). Viaje del mundo, Madrid: Luis Sánchez.

- (1629). Tratado de los reinos orientales y hechos de la reina María y de sus antecesores, y tres comedias famosas, una de: "La mejor legisladora y triunfo de la santísima Cruz», y dos del "Español entre todas las naciones». Compuestas por dos aficionados religiosos. Jaén: Pedro de la Cuesta.

Placer, Gumersindo (1948). "Biografía del Padre Alonso Remón, clásico español”, Estudios, 3, pp. 59-90.

PONTÓN, Gonzalo (2018). "La acotación como texto. Con ejemplos de Lope de Vega". En Luigi Giuliani y Victoria Pineda (eds.), "Entra el editor y dice": ecdótica y acotaciones teatrales (siglos XVI y XVII). Venecia: Ca'Foscari, pp. 69-90.

QueVEDO, Francisco de (2001). La vida del Buscón, ed. Fernando Cabo Aseguinolaza. Barcelona: Crítica.

Remón, Alonso (1629a). Primera parte del Español entre todas las naciones y clérigo agradecido. Jaén: Pedro de la Cuesta.

(1629b). Segunda parte del Español entre todas las naciones y clérigo agradecido. Jaén: Pedro de la Cuesta. (2013). Las grandezas de Madrid. Alicante-Barcelona: Biblioteca Virtual Miguel de Cervantes - Institut del Teatre. En http://www.cervantesvirtual.com/obra/las-grandezas-de-madrid/. [Fecha de consulta: 20 de febrero de 2020] 
- (2016a). El católico español, el emperador Teodosio. En Rosa Durá Celma, El teatro religioso en la colección del conde de Gondomar: el manuscrito 14767 de la BNE. Tesis Doctoral. Valencia, pp. 498-555.

- $\quad$ (2016b). San Jacinto. En Rosa Durá Celma, El teatro religioso en la colección del conde de Gondomar: el manuscrito 14767 de la BNE. Tesis Doctoral. Valencia, pp. 933-1008.

- $\quad$ (s.f.). Las tres mujeres en una. Manuscrito. (Madrid, Biblioteca Nacional de España, Mss. 14896, on line en Biblioteca Digital Hispánica: http://bdh.bne.es/bnesearch/detalle/bdh0000204644) [Fecha de consulta: 20 de febrero de 2020]

RodRíguez CuAdRos, Evangelina (1998). La técnica del actor español en el Barroco. Hipótesis y documentos. Madrid: Castalia.

RodRígueZ-Gallego, Fernando (2018). "Las acotaciones de Calderón. De los autógrafos a las ediciones de Vera Tassis". En Luigi Giuliani y Victoria Pineda (eds.), "Entra el editor y dice": ecdótica y acotaciones teatrales (siglos XVI y XVII). Venecia: Ca'Foscari, pp. 147-190.

RuANO DE LA HAZA, José María (2000). La puesta en escena en los teatros comerciales del Siglo de Oro. Madrid: Castalia.

SERNA LÓPEZ, Vern (1967). "Observaciones sobre el arte de Alonso Remón, dramaturgo lopista". En Actas del II Congreso de la Asociación Internacional de Hispanistas: celebrado en Nijmegen del 20 al 25 de agosto de 1965. Holanda: Asociación Internacional de Hispanistas. Instituto Español de la Universidad de Nimega, pp. 591-597.

- $\quad$ (1982). "Ante Remón y el sacar en limpio sus comedias". En Eugenio Bustos (ed.), Actas del cuarto Congreso Internacional de Hispanistas, vol. 2. Salamanca: Universidad de Salamanca, pp. 633-638.

SmiEJA, Florian L. (2000): "La comedia de San Jacinto de Alonso Remón", Estudios Hispánicos, 8, pp. 13-16.

TIRSO DE Molina (1913). Cigarrales de Toledo. Ed. Víctor Said Armesto. Madrid: Renacimiento.

VAREY, John E. (1987). "La indumentaria en el teatro de Calderón". En Cosmovisión y escenografía. El teatro español en el Siglo de Oro. Madrid: Castalia, pp. 263-272.

VÁZQUEZ, Luis (2004). "El mercedario Fray Alonso Remón, comediógrafo (15611632)". En Ignacio Arellano (ed.), Paraninfos, segundones y epígonos de la comedia del Siglo de Oro. Barcelona: Anthropos Editorial, pp. 41-49.

VEGA, Lope de (1950). Colección escogida de obras no dramáticas, ed. Cayetano Rosell. Madrid: Atlas.

WeinBerg, Bernard (2003). Estudios de poética clasicista: Robortello, Escalígero, Minturno, Castelvetro. Ed. Javier García Rodríguez. Madrid: Arco Libros.

Fecha de recepción: 9 de enero de 2020

Fecha de aceptación: 31 de marzo de 2020 